\title{
Jinan north across the industry to undertake Transfer Strategies
}

\author{
Wang Dongling, ${ }^{1, \text {,* }}$ \\ ${ }^{1}$ Shandong Yingcai University, Jinan, 251401, China \\ a E-mail: 40668058@qq.com
}

Keywords: Shanghe; Jinan North Across; Industrial Transfer

\begin{abstract}
August 31, 2006, in Shandong Building, led by the Shandong Provincial Department of Construction preparation "Jinan metropolitan planning," passed expert review committee, which also marked the Span industrial transfer initially produced. In order to better promote the economic development of Shanghe County, Shanghe should seize the opportunity to develop their own, actively undertake the transfer of Jinan north across the industry.
\end{abstract}

\section{Introduction}

Shanghe located in the northwest of Shandong Province, Jinan municipal County, Shandong Province, under the Jinan City, Jinan City, the northern gate. Shanghe located in Jinan, Dezhou and Binzhou the three border areas, the main gateway to the north of Beijing and Tianjin, Jinan. Due to the river it is located in the border areas, basic near Jinan, Binzhou, Texas, and three break points, away from the main direction of economic ties, development has been greatly restricted. With the rise of the Bohai Economic Circle, Jinan, Shandong Peninsula and improving metropolitan area, Jinan north across industrial transfer further implementation of the strategy, Shanghe will face more opportunities.

August 31, 2006, in Shandong Building, led by the Shandong Provincial Department of Construction preparation "Jinan metropolitan planning," passed expert review committee, which also marked the Span industrial transfer initially produced. "Jinan metropolitan plan" clearly put forward the overall positioning through 15 years of efforts to build a metropolitan Jinan: the Metropolitan Region of Shandong Province; Qilu breeds, City and open innovation culture; landscape shaped wins, livable environmentally friendly metropolitan area; Bohai economic links developed Yangtze River Delta region, the hub for the hinterland Circle: relying Peninsula City, radiating a strong leader of the Yellow River; Bohai Sea south wing of basic industries internationally competitive and advanced manufacturing and services center. Its regional spatial development objectives include: regional urban system optimization and space grow extremely diverse group of urban development, Jinan - Zibo metropolitan area stretching development, urban and industrial centers highly concentrated, intensive levels of small towns optimize the layout of urban agglomerations ; powerful radiating center capabilities and resources of each space, the space body functions integrated development of economic factors, Jinan - Zibo promote integration, joint development of urban centers, urban network-like levels of coupling, space efficient organic structure of metropolitan; area in the urban and industrial agglomeration orderly, relatively balanced urban and rural construction facilities, ecological protection of geographical features complete, harmonious space unit carrying natural space surplus. ${ }^{[1]}$ 
According to 2014 statistics, showing Shanghe economic steady and rapid development, preliminary accounting, in 2014 Shanghe achieve GDP 15.97 billion yuan, up 10 percent over last year. Wherein the first industrial added value of 45.9 billion yuan, up $4.6 \%$; industrial added value of the secondary industry was 61.2 billion yuan, up 13.4\%; the tertiary industry was 52.5 billion yuan, up 10.5\%. Per capita GDP was 27,965 yuan (calculated according to the resident population of 57.1 million), an increase of $10.4 \%$. As can be seen from the above data, Shanghe industrial structure was further optimized. The county consists of three industries in 2013 of 30.2: 37.8: 32.0 adjusted to 2014 28.8: 38.3: 32.9, compared with the previous year, the tertiary industry increased by 0.9 percentage points. Although SHANGHE economy shows steady and rapid development, but the development of the whole county area of Jinan City, the Shanghe ranked eleventh overall level of economic development is still relatively low, or in the downstream. In order to better promote the economic development of Shanghe County, Shanghe should seize the opportunity to develop their own, actively undertake the transfer of Jinan north across the industry.

\section{Shanghe, Jinan north across the industry to undertake Transfer Strategies}

\subsection{First, the full development of their own industries.}

Shanghe has been a traditional agricultural county, the growth of its geographical position more suitable crops, rich in agricultural resources, Shanghe grain, livestock, vegetables and other industries have become the industry has a certain scale, and Shanghe city is also the only one who was awarded the "national food production advanced counties," the counties of the State Council. Shanghe is actively restructuring agriculture to modern agriculture. Construction of livestock demonstration garden, agricultural technology demonstration park and rustic oasis agriculture demonstration zone is rapidly underway. Shanghe melon, bell peppers and garlic and other specialty brands bases are under construction. At present, the municipal urban agriculture park Shanghe has reached more than a dozen, and has formed a "commercial river garlic", "commercial river peppers" a large number of multi-brand agricultural products.

Through the development of its own industries, competitive industries play a competitive advantage, which led to the development of weak industries, the formation of good production, development pattern. Full use of the existing advantages of resources, resources to play the attractiveness of capital, technology and human capital elements to further cultivate and develop new industries.

\subsection{Second, to develop special industries.}

Flower industry. Shanghe is continental warm temperate semi-humid monsoon climate, sunny climate, abundant light, heat and water resources, the average annual temperature of $12.3{ }^{\circ} \mathrm{C}$. Shanghe relatively abundant land resources, soil is sandy loam or loam, more suitable for the growth of flowers. Wherein Shanghe relatively famous flower orchid and anthurium flowers. Shanghe should make use of local advantages of resources, increase investment in technology and cultivate flowers, the introduction of more suitable in the area planted varieties of flowers, floral demonstration park construction. Foreign increase contact with suppliers and investors, the domestic industry to increase inputs and outputs. Achieve internal and external integration, and efficient development.

Mushroom industry. With the improvement of people's living standards, people to meet their basic food and clothing issues, the more focus on health and health care. Edible fungus is a type of organic, nutrition, health care green food, and the mushroom industry is also a set of ecological, economic and social integration in economic development projects. Shanghe is based on farmers' income at the same time, the adjustment of industrial structure, vigorously develop mushroom 
cultivation characteristic industry, particularly in the fungus, black fungus fungus two kinds of industries. Shanghe should strengthen the cultivation of edible fungus technical inputs and training, the constant introduction of new technologies and new varieties, so that mushroom cultivation becoming more and more specialized, large-scale integration.

Leisure and tourism industry. Leisure tourism, while also relaxing the body and mind good. China currently has the largest reserves of Shanghe may utilize geothermal hot spring resources. According to the analysis and determination of geological experts, the hot water is rich in minerals and trace elements silicic acid, strontium, lithium, etc., but these minerals and trace elements beneficial to human body also has high health and medical care effect. In addition, Shanghe County also has many tourist attractions, such as: Jinan modern agricultural technology demonstration park, Dasha tourist scenic zone, Clearwater ecological agriculture sightseeing garden, sand flow Tsui. Future prospects for the development of leisure tourism industry is very impressive, Shanghe should seize the opportunity to develop the region's tourism industry, to create a leisure brand, the implementation of brand, to attract tourists sightseeing. Second, to strengthen infrastructure construction and improve service quality, create a good image of the city.

Features fruit growing industry. Shanghe loose fertile soil suitable for fruit growth. In recent years, with the adjustment of agricultural structure Shanghe, fruit planting industry has developed rapidly, better market prospects. Shanghe should further increase the industry's support and guidance, optimize the industrial structure of agriculture, changes in production and operation mode, promoting Shanghe economic good, and fast development. Learn fruit tree growth characteristics, the introduction and cultivation of the region for the cultivation of fruit trees.

Characteristics of cultural industries. Younger son provider Altair Shandong Province is one of the most representative folk dance, folk dance is the Chinese art treasures. Younger son provider Altair magnificent, dancing aerobics, and contains a splendid history and culture, with a strong appeal and a strong flavor of the times. Precisely because of this, business Altair Younger son at the head of the Shandong three Yangko. Shanghe also in 1996 was named the Ministry of Culture as "rural folk art"; in 2011, the Ministry of Culture announced Shanghe to 2011--2013 annual "Chinese folk culture and arts village"; 2014 was selected 2014-2016 annual "Chinese folk culture and arts village" list. Shanghe county folk art up to more than 30 species. Jinan north across SHANGHE undertake industrial transfer, while can develop their own cultural industry to strengthen its cultural soft power. Strengthen the protection of heritage and cultural characteristics, and vigorously promote its own cultural characteristics, form their own cultural industry advantage.

\subsection{Third, to develop transition.}

With the social development and progress, adjustment and upgrading of industrial structure, the traditional industry is facing problems. To respond positively to the country's scientific development, green development, cycle development, Shanghe should vigorously promote enterprise restructuring and development, in order to better adapt to social development. First, the government and relevant departments should guide enterprises to correct for the transformation of enterprises are increasing support; to have completed the transformation of enterprises should sum up experience and further development. Secondly, we should improve the core competitiveness of enterprises, science and business integration of existing resources, changing the mode of development, to build their own brand. Third, there must be comprehensive view of the overall situation awareness and a sense of crisis, to fully understand the domestic and international economic development of forms and characteristics, combined with their own business realities, the enterprise transformation. 


\subsection{Fourth, increase the industries to relocate to the industry guidance and support.}

Jinan north across the industry for the transfer of commercial river is a huge opportunity, Jinan Shanghe should actively undertake the transfer of industries across the North, and its fundamental purpose is by means of Jinan north across the opportunity to develop their own Shanghe make SHANGHE the economy can achieve sound, rapid development. First, the Government should formulate Shanghe related policies, the introduction of capital elements, especially as such a "soft elements" talent, technology and other more important. Only retain talent and core competencies, in order to better the development of enterprises, the rapid economic development. Second, rational planning, the progressive realization of industrial transfer. In the transfer of industries, we must adjust the industrial structure, to achieve the transfer of industry and north across the local industries combined, ongoing industrial optimization. Third, Shanghe County government and relevant departments to introduce relevant preferential policies to attract investors and to transfer into the industry. North of the Yellow River in Jinan City Jiyang County and Shanghe including global and bridge area of homeland Zhen and large town, if you want to better undertake the transfer of Shanghe, Jinan north across the industry, in addition to their own advantage to start from outside, but also start from the policy. Only the introduction of preferential policies to attract capital and other elements to enter, the only way to seize the Span development opportunities.

\subsection{Fifth, harmonious development, scientific development resources.}

Scientific Concept of Development is the Party's guiding ideology. Only scientific planning and rational use of resources in order to achieve the sustainable use of resources cycle. First, define and develop the localization, implementation of scientific development and utilization. Shanghe because of its special geographical location, rich in natural gas, oil and geothermal resources, especially famous for hot springs, these resources are non-renewable resources. To strictly limit the rough type of development and utilization of resources, we should actively develop intensive use of resources. Secondly, to co-ordinate development and building the whole development system. To natural resources, environment, customs and historical and cultural resources in the region carried out a detailed analysis and assessment of overall planning and development. Standing scientific concept of development height, the overall co-ordination. Third, strengthening the ability to integrate resources, improve resource utilization. To co-ordinate the domain Shanghe economic development, the integration of different resources, so that various industries closely integrated to achieve integrated development. Under the premise of the rational use of resources and effective protection of resources, pollution prevention, and strengthen the construction of facilities in order to achieve harmonious development.

\subsection{Sixth, vigorously support existing industry.}

Shanghe after long-term development, already have their own set of development pattern and industrial structure, actively undertake industrial transfer Jinan north across the same time, leveraging existing strengths to develop industries and special industries, the existing market promising enterprises to vigorously support and to guide. Achieve competitive industries as pillars of development and continue to further the development of specialized industries, foster new enterprises, and constantly optimize the industrial structure, to achieve the transfer of industry and local industries combined common development.

\subsection{Seventh, good investment.}

Promote the construction of major projects, the main problem is the question of money, it should always be the investment as the core task of economic construction work. Shanghe belong to an economically underdeveloped counties, the most effective source of funds is the major investment 
projects. Shanghe should take the lead in their own industries to investment, and the progressive realization of industrial investment promotion; to carry out investment projects; investment in resources. Establish a sound system of investment mechanism, strengthen internal guidance and outreach efforts, creating a strong investment climate and a good investment environment.

\section{Acknowledgements}

Project of Shandong Provincial Bureau of statistics 2016(KT16133); Shandong social science program (15CSGZ15)

\section{References}

[1]"Jinan metropolitan planning", Shandong Provincial Department of Construction, January 2007 